\title{
Pengembangan video animasi materi lambang negara indonesia untuk meningkatkan motivasi belajar dan daya ingat peserta didik kelas iii di mi ma'arif pamotan
}

\author{
Titsa Raky Andjani ${ }^{1}$

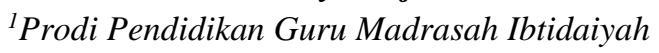 \\ Fakultas Agama Islam \\ Universitas Muhammadiyah Sidoarjo \\ Email: titsa1998@gmail.com
}

\begin{abstract}
Education in Indonesia must have an effort to develop creative, affective and quality learning activities so that the knowledge possessed has a long-term impact. This research uses R\&D (Research and Development) research methods. R\&D methods are often used to make products or develop products beforehand. In addition, researchers in collecting data through interviews with informants at MI Ma'arif Pamotan, observation and documentation. In analyzing the results of interviews regarding the lack of memory of students on state emblem material, researchers analyzed using the quantitative analysis technique of percentage and paired t-test analysis techniques.

From the two analytical techniques in the study, it is known that the results of the validation questionnaire assessment from the experts stated that the textbook products developed by researchers are feasible to be applied in schools to overcome learners who lack preformance in learning motivation and memory.
\end{abstract}

Keywords: video animation, learning motivation, memory

\section{PENDAHULUAN}

Pendidikan di Indonesia harus memiliki upaya untuk mengembangkan kegiatan pembelajaran yang kreatif, afektif dan bermutu agar ilmu pengetahuan yang dimiliki berdampak jangka panjang. [1] Untuk mewujudkan pembelajaran yang kreatif, efektif dan efisien, penggunaan metode belajar, model, dan media belajar sangat berpengaruh penting.[2]

Media pembelajaran merupakan bagian dari sumber belajar yang didapat dari kombinasi perangkat lunak (bahan belajar) dan perangkat keras (alat belajar). Dengan adanya media dapat membantu peserta didik menerjemahkan hal-hal abstrak menjadi hal yang kongkret dan mudah di pahami. Media belajar memiliki beberapa macam diantaranya: media visual, audio, dan audio visual. Setiap jenis memiliki fungsi dan manfaat yang berbeda-beda.[3] Media belajar diharapkan mampu memberikan inovasi baru dalam penyampaian materi belajar kepada penerima informasi atau peserta didik. [3] Media belajar yang digunakan pada kegaitan belajar mengajar sangat banyak, misalnya modul, buku cerita, pop up, bahkan video animasi.

Video animasi merupakan perantara dalam menyampaikan sebauh informasi dengan bantuan ilmu teknologi sehingga menghasilkan ilustrasi gambar sesuai dengan kebutuhan media yang diinginkan. [4] Video animasi terdiri atas video animasi dua dimensi dan video animasi tiga dimensi. [5] Adanya media belajar video animasi mampu memberikan kemudahan bagi pendidik, pendidik dapat memutar kembali video jika peserta didik belum memahami materi. Selain itu dampak baik untuk peserta didik yaitu hasil belajar, motivasi belajar dan tidak mudah bosan karena pembelajaran yang berbeda.[3]

Motivasi mempunyai pengaruh kepada peserta didik untuk semangat belajar dan peningkatan keinginan belajar peserta didik.[6] Motivasi belajar ialah kemampuan yang muncul dari dalam diri seseorang maupun dorongan dari lingkungan luar untuk menuju perubahan yang lebih baik dari sebelumnya dalam hal penerimaan ilmu pengetahuan. [6], [7]. Dengan adannya peningkatan motivasi belajar, diharapkan peserta didik lebih memahami materi secara menyeluruh dan memberikan dampak pada hasil belajar peserta didik. 
Daya ingat adalah tempat penyimpanan pengetahuan-pengetahuan yang diperoleh, dengan artian tepat untuk menampung, merekam, dan merespon informasi yang didapat agar mampu disampaikan kembali pada waktu yang dibutuhkan.[8], [9] Untuk meningkatakan daya ingat peserta didik, pendidik harus mengatahui perkembangan kognitif setiap jenjang.

Lambang negara adalah bentuk untuk menggambarkan identitas, kejayaan bahkan kepribadian negara tersebut agar tercapai sebuah cita-cita yang diinginkan dan setiap negara didunia memiliki bentuk lambang yang berbeda.[10] Seperti halnya negara Indonesia, simbol lambang negara Indonesia adalah burung garuda. Pemilihan burung garuda sebagai lambang negara sesuai dengan perjalanan memperoleh kemerdekaan bangsa.

Namun saat ini sikap yang ditunjukkan masyarakat mencerminkan ketidak pedulian akan makna lambang negara Indonesia, misalnya yang terjadi di lapangan segelintir peserta didik ada yang tidak hafal sila pancasila, menyanyikan lagu nasional dengan sikap atau posisi badan yang tidak siap, tidak mengetahui dengan jelas makna-makna yang terkandung disetiap bagian lambang negara, dan masih banyak lagi. Maka dati penetilian ini ingin membahas lambang negara Indonesia berserta makna yang tergaandung dan dikemas pada media belajar video animasi dua dimensi.

Penelitian ini akan membahas efetifitas dan efisiensi pengembangan video animasi 2 dimensi materi lambang negara Indonesia untuk meningkatkan motivasi belajar dan daya ingat peserta didik di $\mathrm{MI}$ Ma'arif Pamotan sehingga mampu dijadikan sebagai media pendamping pembelajaran, meningkatkan daya ingat dan motivasi peserta didik dalam jangka panjang dan menghilangkan rasa bosan peserta didik terhadap pembelajaran ppkn meteri lambang Negara Indonesia.

\section{METODE PENELITIAN}

Lokasi penelitian dan pengembangan video animasi materi lambang negara dilakukan di MI Ma'arif Pamotan Ds. Porong Sidoarjo. Dengan jumlah peserta didik yang awalnya 38, namun karna pandemi dan kebijakan sekolah mengijikan 10 peserta didik untuk penelitian. Peserta didik dipilih berdasarkan kedekatan jarak rumah kesekolah.

Model penelitian menggunakan model Brog \& Gall. Model Brog and Gall memiliki 10 langkah dalam proses pengembangan dan mengarah untuk modifikasi produk sesuai dengan kebutuhan penelitian.[11] 10 langkah proses pengembangan Brog and Gall sebagai berikut:

Gambar 2.1 10 Tahapan Brog and Gall

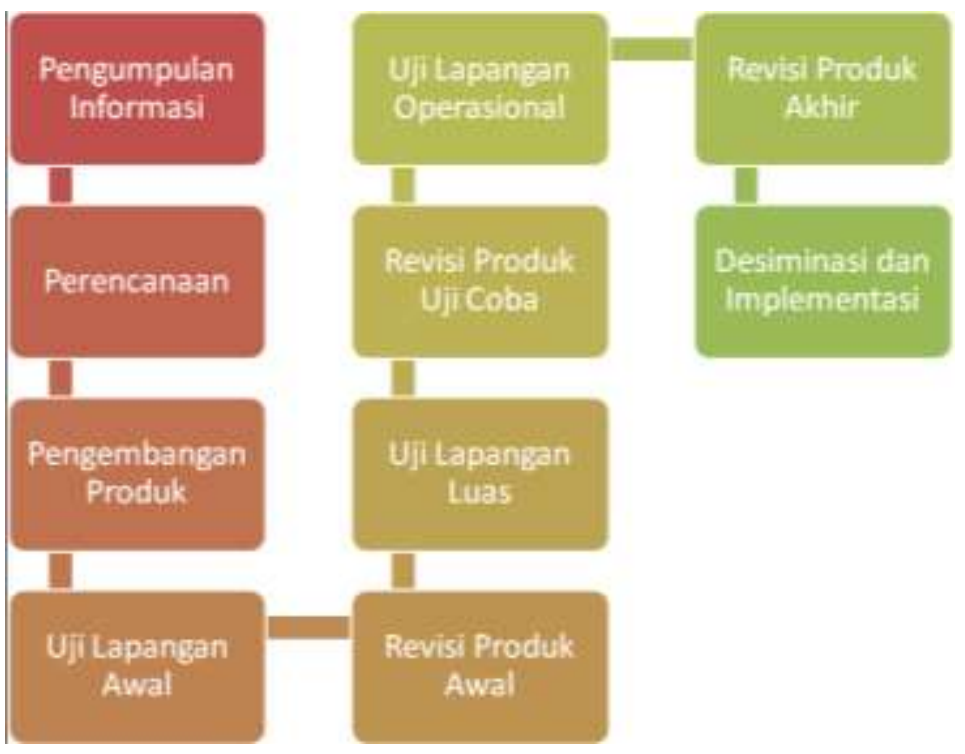


Namun pada penelitian ini hanya menggunakan 7 tahapan karena kendala pandemi covid-19. Tahapan dalam pengembangan penelitian, yaitu: meneliti dan pengumpulan informasi, perencanaan, pengembangkan produk yang sudah ada, uji lapangan awal, revisi produk awal, uji coba lapangan lebih luas, revisi produk hasil uji coba.

Instrumen pengumpulan data menggunakan pedoman: wawancara, kuesoner dan pos-test. Analisis data menggunakan data kuantitatif dan kualitatif. Teknik menggunakan Analisis Paired T-Test. Teknik analisis data berguna untuk mengetahui kelayakan dan afektifitas video animasi 2 dimensi materi lambang negara dengan bantuan program spss. Analisis data kuantitatif diambil dari perolehan angka validasi produk yang sudah diterima.

Pemberian nilai disetiap indikator bertujuan memberikan penjelasan untuk pengukuran kelayakan produk pengembangan. Teknik analisis kuantitatif memiliki ketetapan penilaian. Hasil penilaian pada penilitian ini yaitu diambil dari data validitas yang sudah diberikan para ahli, baik ahli materi, bahasa, dan desain. Scoring penilaian validitas ahli telah ditabulasikan untuk media belajar video animasi lambang negara Indonesia di MI Ma'arif Pamotan Sidoarjo seperti berikut:[12]

Tabel 2.1 Scoring kelayakan validasi ahli

\begin{tabular}{cll}
\hline Skor & Persentase & Keterangan \\
\hline 4 & $100 \%-90 \%$ & Sangat layak \\
3 & $89 \%-79 \%$ & Layak \\
2 & $78 \%-68 \%$ & Cukup layak \\
1 & $67 \%-57 \%$ & Kurang layak \\
\hline
\end{tabular}

\section{HASIL DAN PEMBAHASAN}

Hasil validasi penelitian dan pengembangan media video animasi materi lambang negara menggunakan dua penyajian penilaian, yakni kuantitatif dan kualitatif. Teknik analisis kuantitatif seperti penjelasan dibawah ini:

Tabel 3.1 Tabulasi Kelayakan Ahli Materi

\begin{tabular}{cccc}
\hline Peryataan & $\mathbf{X}$ & $\mathbf{x i}$ & Persentase \\
\hline Jumlah & 29 & 32 & $90,6 \%$ Sangat layak \\
\hline
\end{tabular}

Tabel 3.2 Tabulasi Hasil Validasi Ahli Desain

\begin{tabular}{crccc}
\hline No. & Peryataan & $\mathbf{X}$ & $\mathbf{X i}$ & Persentase \\
\hline 1. & Jumlah & 32 & 32 & $100 \%$ Sangat layak \\
\hline
\end{tabular}

Tabel 3.3 Tabulasi Hasil Validasi Ahli Bahasa Tahap 1

\begin{tabular}{ccccc}
\hline No. & Peryataan & $\mathbf{X}$ & $\mathbf{X i}$ & Persentase \\
\hline 1. & Jumlah & 13 & 20 & $65 \%$ Kurang layak \\
\hline
\end{tabular}

Tabel 3.4 Tabulasi Hasil Validasi Ahli Bahasa Tahap 2

\begin{tabular}{rrrrc}
\hline No. & Peryataan & $\mathbf{X}$ & $\mathbf{X i}$ & Persentase \\
\hline 1. & Jumlah & 15 & 20 & $75 \%$ Cukup layak \\
\hline
\end{tabular}




\section{Keterangan:}

$\mathrm{x} \quad$ : jumlah skor perolehan kuesoner ahli

xi : skor maksimal kuesoner

\% : $\quad$ x dibagi xi dikali 100

100 :konstanta

Dari hasil persentase ketiga ahli yaitu ahli materi, ahli desain, dan ahli bahasa pengembangan video animasi materi lambang negara Indonesia layak sesuai dengan ketentuan scoring validitas pada tabel 1.1. Pada validasi ahli materi dan desain dikatakan layak karena tidak ditemukan kesalahan sedangkan hasil validasi ahli bahasa mengalami pembetulan sebanyak 3 kali sehingga ditemukannya 2 tahapan pembetulan. Sedangkan teknik analisis kualitatif untuk uji kelayakan validasi ahli diambil dari data saran dan kritik:

Tabel 3.5 Penjelasan saran dan kritik ahli bahasa

\begin{tabular}{|c|c|c|}
\hline Nama & Ahli & Saran dan kritik \\
\hline Imam Wahyudi, S.P.d & Materi & $\begin{array}{l}\text { Lebih teliti dan koreksi dulu scene yang akan } \\
\text { buat }\end{array}$ \\
\hline Dr. Nurdyansyah, M.Pd. & Desain & $\begin{array}{l}\text { Secara keseluruhan sudah Aplikasi sudah bagus } \\
\text { dan penjelasan deskriptif dan naratif cukup } \\
\text { bagus dan mudah dipahami }\end{array}$ \\
\hline Ruli Astuti, S.S., M.Pd. & Bahasa & $\begin{array}{l}\text { Perbaiki ejaan sesuai EYD, perhatikan } \\
\text { penggunaan huruf kapital yang benar, } \\
\text { penyampaian materi terlalu cepat, seharusnya } \\
\text { agak diperlambat agar dapat disimak dengan } \\
\text { baik oleh peserta didik. }\end{array}$ \\
\hline
\end{tabular}

Setelah mengetahui kelayakan media belajar pengembagan video animasi materi lambang negara Indonesia dari perhitungan persentase validasi para ahli dikatakan layak. Langkah selanjutnya yang dilakukan peneliti yaitu teknis analisis paired t-test. Teknik analisis paired t-test bertujuan untuk mengatahui pengaruh video animasi materi lambang negara Indonesia apakah efektif dan layak untuk meningktakan motivasi belajar dan daya ingat peserta didik di MI Ma'arif Pamotan. Data diambil dari hasil pretest dan postest peserta didik. Berikut hasil analisis:

Tabel 3.6 Analisis Paired Samples Statistics

\begin{tabular}{|c|c|c|c|c|c|c|}
\hline & & Mean & $\mathrm{N}$ & & Std. Deviation & Std. Error \\
\hline Pair & Pre test & 53.30 & & 10 & 15.399 & 4.870 \\
\hline 1 & $\begin{array}{l}\text { Pos } \\
\text { test }\end{array}$ & 93.30 & & 10 & 5.968 & 1.887 \\
\hline
\end{tabular}

Pada tabel paired samples statistics bertujuan untuk mengetahui rata-rata perbedaan antara pre test dan pos test. Nilai rata-rata pre-test materi lambang negara adalah 53.30, sedangkan nilai rata-rata post-test yaitu 87.30. Hasil mean pada Tabel analisis paired samples statistics diatas perbedaan rata-rata. Data tersebut dapat dibaca nilai rata-rata pre-test $53.30<$ post-test 87.30 . 
Tabel 3.7 Tabulasi Paired Samples Correlations

\begin{tabular}{llllll}
\hline & $\mathrm{N}$ & & Correlation & \multicolumn{2}{c}{ Sig. } \\
\hline Pair $1 \quad \begin{array}{l}\text { pre test \& pos } \\
\text { test }\end{array}$ & 10 & .702 & .024 \\
& & & & & \\
\hline
\end{tabular}

Pada tabel paired samples correlations bertujuan untuk memberikan informasi hubungan antara data pretest dan post-test. Colom correlation dari tabel diatas sebesar 0,702 nilai signifikansi 0.024 . Data tabel diatas dapat disimpulkan tidak ada hubungan antara pre-test dan post-test, karena nilai signifikansi > dari pada 0,05 . Sein itu data diatas dapat diketahui jumlah responden dari colom $\mathrm{N}$ yaitu 10 peserta didik.

Tabel 3.8 Tabulasi Paired Samples Test

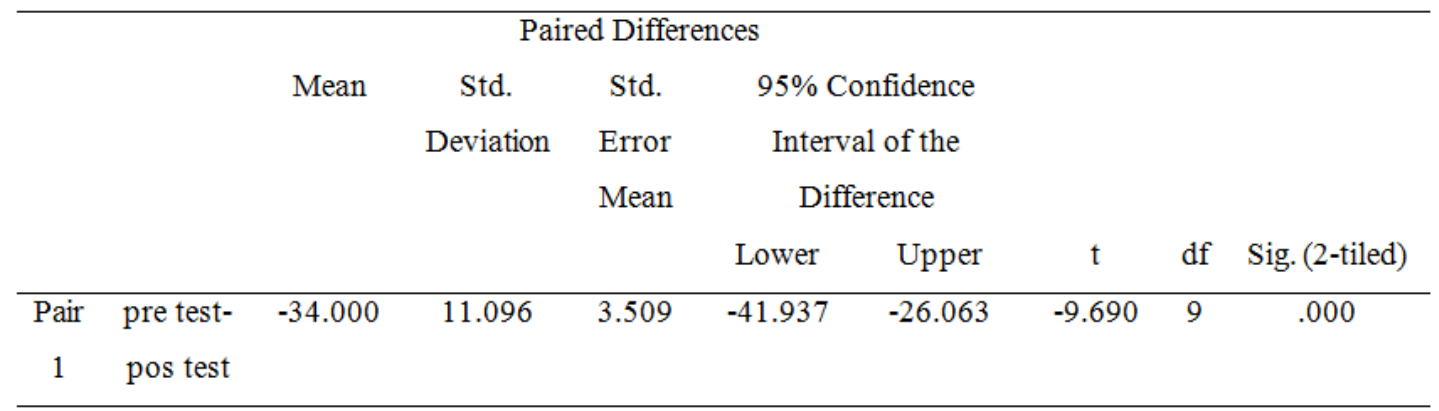

Pada semua tabel analisis paired t-tes tabel Tabel 3.8 sangat penting dari yang sudah dipaparkan sebelumnya.

Analisis paired samples test berguna untuk memperoleh jawaban apakah terdapat pengaruh dari penggunaan media belajar video animasi 2 dimensi materi lambang negara Indonesia untuk meningkatkan motivasi belajar dan daya ingat peserta didik. Untuk mengtahui terdapat pengaruh atau tidak dilihat dari kolom sig.(2-tailed). Kolom sig.(2-tailed) memperoleh hasil probabilitas sebesar 0,000. Maka dari itu dapat dikatakan bahwa $0,000<0,05$ sehingga disimpulkan media belajar video animasi materi lambang negara Indonesia memiliki pengaruh untuk meningkatkan motivasi dan daya ingat persta didik di MI Ma'arif Pamotan Sidoarjo.

Pada penelitian dan pengembangan video animasi materi lambang negara Indonesia untuk meningkatkan motivasi belajar dan daya ingat peserta didik kelas 3 di MI Ma'arif Pamotan menunjukkan hasil bahwa layak untuk diterapkan pada proses belajar mengajar. Pernyataan tersbut selaras dengan hasil analisis yang sudah dipaparkan penjelasan diatas. Akan tetapi hasil analisis tidak semata-mata dijadikan patokan utama untuk mengetahui layak dan effektifan sebuah produk. 
Selain hasil persentase validasi ahli dan analisis paired t-test untuk menetukan kelayakan dan effektifnya produk video animasi materi lambang negara Indonesia adalah perubahan sikap sebelum dan sesudah ditunjukkan media, serta peningkatan hasil belajar yang dilihat dari perolehan nilai pre test dan post tes peserta didik kelas 3 di MI Ma'arif Pamotan Sidoarjo.

Dari hasil dari pengamatan peneliti, perilaku peserta didik sebelum ditunjukan media peserta didik lebih sibuk dengan teman sebangku, namun berbeda saat peserta didik menerima materi belajar didampingi dengan media belajar video animasi 2 dimensi materi lambang negara Indonesia, perta didik lebih terarah dan menyimak setiap scene yang ada pada video animasi.

Sedangkan hasil belajar peserta didik MI Ma'arif Pamotan yang dijadikan subjek penelitian pada pegembangan media belajar ini mengalami peningkatan. Pernyataan tersebut selaras dengan hasil pre-test maupun post-test. Hasil pre test lebih sedikit dari pada hasil post test

Dapat disimpulkan bawah penelitian pengembangan video animasi materi lambang negara Indonesia untuk meningkatkan motivasi belajar dan daya ingat peserta didik dikatakan layak dan efisien di terapkan terhadap peserta didik kelas 3 di MI Ma'arif Pamotansebagai media pendamping pembelajaran.

\section{KESIMPULAN}

Hasil persentase ahli materi, ahli desain, dan ahli bahasa pengembangan video animasi materi lambang negara Indonesia layak sesuai dengan ketentuan scoring validitas pada tabel 1.1. Pada validasi ahli materi dan desain dikatakan layak karena tidak ditemukan kesalahan sedangkan hasil validasi ahli bahasa mengalami pembetulan sebanyak 3 kali sehingga ditemukannya 2 tahapan pembetulan. Hasil persentase yang diperoleh dari ahli desain yaitu $100 \%$, dari ahli bahasa sebesar $75 \%$, dan dari ahli materi sebesar 90,6\%. Hasil dari persentase mengartikan bahwa produk pengembangan media belajar video animasi 2 dimensi layak digunakan. Produk pengembangan media belajar video animasi dinyatakan efektif, berdasarkan pembuktian analisis uji sampel paired t-test. Probabilitas 0,000<0,05 dapat disimpulkan bahwa media belajar video animasi materi lambang negara Indonesia memiliki pengaruh untuk meningkatkan motivasi dan daya ingat persta didik di MI Ma'arif Pamotan Sidoarjo, sehingga video animasi 2 dimensi efektif untuk kegiatan belajar mengajar materi lambang negara Indonesia di MI Ma'arif Pamotan Sidoarjo.

\section{REFRENCES}

[1] S. Z. Dewi and I. Hilman, "Penggunaan TIK sebagai Sumber dan Media Pembelajaran Inovatif di Sekolah Dasar," Indones. J. Prim. Educ., vol. 2, no. 2, p. 48, 2019.

[2] T. S. H. Noviyanto, N. Juanengsih, and E. S. Rosyidatun, "Penggunaan Media Video Animasi Sistem Pernapasan Manusia Untuk Meningkatkan Hasil Belajar Biologi,” Edusains, vol. 7, no. 1, pp. 5763, 2015.

[3] A. Muhson, "Pengembangan Media Pembelajaran Berbasis Teknologi Informasi," J. Pendidik. Akunt. Indones., vol. 8, no. 2, 2010.

[4] U. Wuryanti and B. Kartowagiran, "Pengembangan Media Video Animasi Untuk Meningkatkan Motivasi Belajar Dan Karakter Kerja Keras Siswa Sekolah Dasar,” J. Pendidik. Karakter, vol. 6, no. 2, pp. 232-245, 2016.

[5] N. Risdayanti, "Pengembangan Media Pembelajaran Berbasis Video Animasi Menggunakan Sketchup Pada Metode Pelakasanaan Pekerjaan Arsitektur Konstruksi Bangunan Gedung Bertingkat Rendah," J. Pendidik. Tek. Sipil dan Perenc., vol. 5, no. 3, pp. 1-7, 2017.

[6] G. Hamdu and L. Agustina, "Pengaruh Motivasi Belajar Siswa Terhadap Prestasi Belajar IPA di Sekolah Dasar," Penelit. Pendidik., vol. 12, no. 1, pp. 81-86, 2011.

[7] S. Yanti, E. Erlamsyah, and Z. Zikra, "Hubungan antara Kecemasan dalam Belajar dengan Motivasi Belajar Siswa,” Konselor, vol. 2, no. 1, pp. 283-288, 2013.

[8] W. Prasetyo and S. A. Saputra, "Pengaruh Senam Otak Terhadap Daya Ingat Anak Kelas V Sekolah Dasar,” J. Chem. Inf. Model., vol. 53, no. 9, pp. 1689-1699, 2013.

[9] T. Raharjo, "Peningkatan Kemampuan Daya Ingat Anak Slow Learner Melalui Terapi Kognitif Pada Anak Sekolah Dasar,” J. Sos. Budaya, vol. 5, no. 1, pp. 34-41, 2012. 
[10] L. Safrina, "Tinjauan Hukum Islam Terhadap Ancaman Pidana Bagi Pelaku Penodaan Lambang Negara RI,” LEGITIMINSI, vol. VI, no. 24, pp. 213-231, 2017.

[11] S. Haryati, "Research and Development (R\&D) Sebagai Salah Satu Model Penelitian dalam Bidang Pendidikan," Res. Dev. Sebagai Salah Satu Model Penelit. Dalam Bid. Pendidik., vol. 37, no. 1, pp. 11-26, 2012.

[12] I. Effendy, "Pengaruh Pemberian Pre-Test dan Post-Test Terhadap Hasil Belajar Mata Diklat HDW.DEV.100.2.a pada Siswa SMK Negeri 2 Lubuk Basung,” J. Ilm. Pendidik., vol. 1, no. 2, pp. 81$88,2016$.

[13] Irgashevich, D. A. (2020). Development of national network (tas-ix). ACADEMICIA: An International Multidisciplinary Research Journal, 10(5), 144-151. Article http://dx.doi.org/10.5958/2249-7137.2020.00254.2

\title{
SURAT PERNYATAAN SESUAI PANDUAN PENULISAN
}

\author{
Yang bertandatangan di bawah ini, saya: \\ Nama Mahasiswa : Titsa Raky Andjani \\ NIM $: 162071200010$ \\ Program Studi Pendidikan Guru Madrasah Ibtidaiyah (PGMI) \\ Fakultas : Agama Islam
}

MENYATAKAN bahwa, artikel ilmiah saya dengan rincian:

Judul :Pengembangan Video Animasi Materi Lambang Negara Indonesia untuk Meningkatkan Motivasi Belajar dan Daya Ingat Peserta Didik Kelas III di Mi Ma'arif Pamotan

Kata Kunci Video animasi, motivasi belajar, daya ingat

\section{TELAH:}

1. Disesuaikan dengan petunjuk penulisan dari jurnal ilmiah di Universitas Muhammadiyah Sidoarjo. Berdasarkan Surat Keputusan Rektor UMSIDA tentang Standar Penulisan Karya Tulis Ilmiah dan Plagiarisme di Universitas Muhammadiyah Sidoarjo.

2. Lolos uji cek kesamaan sesuai ketentuan yang berlaku di Universitas Muhammadiyah Sidoarjo.

Serta BELUM PERNAH dan TIDAK AKAN dikirimkan ke jurnal ilmiah manapun, tanpa seizing dari Pusat Pengembangan Publikas illmiah UMSIDA.

Demikian pernyataan dari saya, untuk dipergunakan sebagaimana mestinya. Terima Kasih

Mengetahui,

Dosen Pembimbing

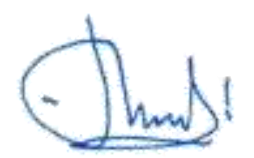

(MOCH. BAHAK UDIN BY ARIFIN, M.Pd.I)

NIDN. 0704018803
Sidoarjo, 13 Agustus 2020

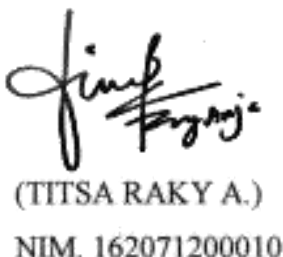

NIM. 162071200010 